\title{
THE INTERMEDIATE LEARNER'S CHOICE OF SELF-AS-A- MODEL STRATEGIES AND THE EIGHT-SESSION PRACTICE IN LEARNING OF THE FRONT CRAWL SWIM
}

\author{
Priscila Garcia Marques ${ }^{1}$, Regina Alves Thon ${ }^{2}$, Janaina Espanhol ${ }^{3}$, \\ Go Tani ${ }^{4}$, and Umberto Cesar Corrêa ${ }^{4}$ \\ ${ }^{1}$ States University of Maringá, Paraná, Brazil \\ ${ }^{2}$ Unipar, Toledo, Paraná, Brazil \\ ${ }^{3}$ Federation of Water Sports of Paraná, Brazil \\ ${ }^{4}$ University of São Paulo, São Paulo, Brazil
}

Original scientific paper

UDC: $797.212 .4: 159.937$

\begin{abstract}
:
The aim of this study was to investigate the intermediate learners' choice of self-as-a-model strategies for learning the front crawl swim by extending the amount of practice. Participants $(\mathrm{n}=40)$ were divided into three groups: choice (free to choose to watch a video footage of their best or overall performance anytime during a practice), yoked (paired to the learners of the choice group), and control group (did not watch any video). Experimental design also involved a pretest, eigh tacquisition blocks, and a 48-hour retention test. The measures included a qualitative analysis of the front crawl swim and the rate of self-efficacy belief questionnaire. Results showed better learning of the front crawl swim for the choice group in comparison to the yoked and control group. It was also verified that the belief of self-efficacy improved in the choice and yoked groups. Most learners chose self-observation of their overall performance during the entire practice. The rest of learners waved in their choices. Self-observation of either the best or overall performance had similar effects on learning the front crawl swim. In conclusion, to provide learners with freedom of choice during the extended acquisition phase was positive for motor learning, regardless of whether or not there were changes in their choices.
\end{abstract}

Key words: freedom of choice, self-observation strategies, motor learning, amount of practice

\section{Introduction}

In the last few years, the observation of one's own performance, i.e. self-as-a-model strategy, has been proposed as an important means of understanding the motor learning process (Clark \& SteMarie, 2007; Dowrick, 2012; Rymal, Martini, \& Ste-Marie, 2010; Starek \& McCullagh, 1999; SteMarie, Vertes, Law, \& Rymal, 2012). This strategy has been divided into two categories: self-observation of the best performance and self-observation of overall performance, also referred to as selfmodel and self-observation, respectively (Dowrick, 1999; Martini, Rymal, \& Ste-Marie, 2011). The selfobservation of the best performance functions as a positive self-review and feedforward because the learner sees what he/she did best (Dowrick, 2012). On the other hand, in the self-observation of overall performance the learner also observes his/her own performance, but it includes both his/her mistakes and best performances.
In general, the literature on this subject has suggested that the observation of one's own performance enables learners to correct their errors and improve their self-efficacy belief. This occurs mainly because the self-as-a-model strategy implies self-regulated learning in wich learners control their own performance via self-evaluation (see Clark, Ste-Marie, \& Martini, 2006; Marques \& Corrêa, 2016; Martini, et al., 2011; Rymal, et al., 2010; SteMarie, et al., 2012).

It seems that literature leaves no doubt that observing one's own performance is more beneficial to learning than no observation. However, when the types of self-as-a-model (observation of either the best or overall performance) are compared, results remain inconclusive. For example, although some studies demonstrated higher benefits to motor learning achieved by the self-observation of the best performance (Clark, et al., 2006; Clark \& SteMarie, 2007; Dowrick \& Raenbun, 1995), others 
revealed no differences between self-observation of either the best or overall performance (Martini, et al., 2011; McCullagh \& Meyer, 1997; Ram \& McCullagh, 2003; Winfrey \& Weeks, 1993).

To advance this problem, recent studies have considered the learner's freedom of choice as an important characteristic of the self-regulation process underpinning the effects of self-as-a-model strategy on the motor skill acquisition (Ste-Marie, et al., 2012). In fact, a considerable amount of research in the motor learning field has suggested that providing learners with freedom of choice in some aspect of the practice (i.e.self-controlled learning) would engage them more actively in their learning process. As a consequence, they would process more deeply the key information related to performance, increase their feelings of self-efficacy, and enhance their effort, persistence, and responsibility for learning (Chiviacowsky \& Wulf, 2005; Marques \& Corrêa, 2016; Patterson, Carter, \& Sanli, 2011).

In this concern, a recent study by Marques and Corrêa (2016) investigated the effects of learners' self-observation choice to view either the best or overall performance on motor learning of the front crawl swim. They conducted two experiments that differed in terms of learner's characteristics or stage of learning (i.e. participants were either novice or intermediate learners of the front crawl swim). Experimental design comprised three groups for both experiments: choice (before each practice session learners chose the video footage they wanted to watch: either the best or overall performance); yoked (the types of self-as-a-model were matched to those of choice group); and control (did not observe self-as-a-model videos). Results showed that the beginners who had freedom of choice (i.e. who retained their control on the type of self-asa-model strategy) were better in motor learning and had a higher rate of self-efficacy belief than the yoked and control group learners. As regards the intermediate learners, results revealed only an increase in self-efficacy beliefs.

Notwithstanding these findings, two aspects of the results warrant attention. First, the effects of the types of self-as-a-model on learning of the front crawl swim could not be compared because the learners chose to watch only their overall performance. Why did learners prefer to watch their overall performance instead of their best performance? It was hypothesized that this occurred because the amount of practice (four sessions) was not enough to lead learners to a desired accurate level of performance to the point they wanted to see their best performance. It was supposed that, although observation of the overall performance can help beginners and intermediate swimmers comprehend what should be done and associate their errors in performance to the intended movement patterns, respectively (e.g. coordination acquisition process; Newell, 1985), observation of the best performance would help them refine their performance towards the 'optimum' desired performance (e.g. control acquisition process; Newell, 1985). In other words, learners would choose to see their best performance to get details to refine it. It is possible that if the practice had been extended, learners would have gained refined control of the task and, consequently, would have made more appropriate choices for their needs, including observation of their best performance.

In fact, with regard to this, the second aspect of the results of Marques and Corrêa (2016) that drew attention was that performances of the choice group (exp. 1) and the choice and yoked groups (exp. 2) showed the tendency to continue improving (i.e. no stabilization of their performances was observed). Although Starek and McCullagh (1999) provided supporting evidence for the benefit of observation of the best performance to learning the front crawl swim through four practice sessions, it is important to highlight that protocol did not comprise a group that observed overall performance. Therefore, we sought to advance the existing knowledge by investigating learners' choice in relation to selfas-a-model strategies in learning the front crawl swim by extending the amount of practice.

\section{Methods}

\section{Participants}

Forty college students, both male $(n=18)$ and female $(n=22)$, with an average age of $21.2 \pm 1.94$ years, took part in this experiment.

The experimental protocol was based on previous studies (e.g. Clark \& Ste-Marie, 2007; Marques \& Corrêa, 2016; Starek \& McCullagh, 1999). Thus, the inclusion criteria were as follows: (a) to be older than 18 years; (b) to be at least 1.75 $\mathrm{m}$ in height to enable the evaluation via swimming footage; (c) to not have any respiratory problems or muscle-joint issues that would interfere with the swimming performance, (d) to be physically active, (e) to show a minimum rate of $60 \%$ of motivation for learning the front crawl according to the Clark, Ste-Marie, and Martini's (2006) questionnaire, and finally, according to the main study's concern, to obtain between $30 \%$ and $55 \%$ of success in the front crawl swim based on a specific checklist, which would characterize the participants as intermediate swimmers (Madureira, Bastos, Corrêa, Rogel, \& Freudenheim,2012).

\section{Task and equipment}

The task was the front crawl swim. We used a JCV Everio HD® camera, GZ300, resolution 
1080/60P, 3CCD, 200x digital and 10x optical zoom used at a frequency of $60 \mathrm{~Hz}$ for aerial footage, and a HD Camera AEE Xtrax of Sports ${ }^{\circledR}$ model SD20, picture setting $1080 / 60 \mathrm{P}$, at a frequency of $30 \mathrm{~Hz}$ for underwater footage. Virtualdub 13.0 software was used for editing videos. To display the videos available to the learners before the practice session, we used an HP Ultrabook ${ }^{\circledR}$ brand 14' Intel core $13 \AA$ computer; the software used to run the videos was the Kinovea 7.0.

\section{Design and procedures}

The study involved three experimental phases: pretest, acquisition period, and retention test. During the pretest, the participants were filmed while swimming the front crawl for $25 \mathrm{~m}$ so that the experimenters could check that they were intermediate swimmers and had similar performance level. Before the acquisition phase, which comprised eight practice sessions conducted on consecutive days, participants were randomly assigned into three groups:

(1) Choice $(\mathrm{n}=15)$. The learners could choose the video they wanted to watch: either their best or overall performance. Before each session, the experimenter asked the learner if he/she wants to change his/her choice of the previous session.

(2) Yoked $(n=15)$. The learners in this group were paired to the choice group learners. The types of video the learners in this group watched were matched to the ones of the choice group (overall or best performance).

(3) Control $(\mathrm{n}=10)$. This group did not have self-asa-model.

All performances were edited by considering the central 10-25 m swim. The videos of the control group, however, were utilised only for the assessment of swimming performance. The videos of learners who chose to watch their overall performance (and their respective yoked group learners) required only cutting out the specific $10 \mathrm{~m}$. And for those who chose to watch their best performance, the videos required editing by an expert who selected, based on the checklist of the front crawl swim, the best interval for those $10 \mathrm{~m}$. Similar to previous studies (Clark, et al., 2006; Clark \& Ste Marie, 2007; Marques \& Corrêa, 2016), the selected piece of the footage was cut out again and repeated to match the length of one minute for all learners.

The choice group learners were instructed to choose to watch what they wanted to see in terms of their either overall or best performance. In addition, they were also instructed to observe how they performed the front crawl swim while they watched the video. Learners of all the three groups performed the front crawl during the 30-minute sessions, including a an 8-minute rest every two swims pools.
Similar to the study by Marques and Corrêa (2016), two expert observers evaluated the crawl swim. In this case, both intra-reliability $(\mathrm{r}=.90)$ and inter-reliability $(\mathrm{r}=.93)$ were considered. The acquisition phase involved eight sessions, on consecutive days. A retention test consisted of performing the same $25 \mathrm{~m}$ task 48 hours after the acquisition phase but with no self-as-a model strategy.

\section{Measurements}

The measures included (a) the qualitative analysis of the front crawl swim score and (b) the scale of self-efficacy beliefs evaluation. The performance of the front crawl was assessed using a checklist for qualitative assessment of the front crawl (Madureira, et al., 2012). This checklist involves scores related to a category of 12 errors of performance: (1) attack and recovery; (2) release; (3) synchronisation of the upper limbs; (4) respiration; (5) synchronisation between the upper limbs and respiration; (6) scan down; (7) scan inside; (8) upward sweep; (9) body positioning; (10) the lower limbs; (11) synchronisation between the lower limbs and breath; and (12) synchronisation between the lower and upper limbs. The errors for each component are contralateral and are weighted between 0.5 and 1.0 for items $6,7,8$, and 10 and 1.5-2.0 for other items. If no error occurs, 0 is assigned. The scores are based on the errors with a maximum score of 152 . Thus, the lower the score, the better the performance. The last $25 \mathrm{~m}$ learners swam in each acquisition block was filmed, which allowed for subsequent evaluation.

Self-efficacy belief was assessed using the General Perceived Self-Efficacy Scale (EAEGP; Bandura, 2006), which was validated for the Portuguese language by Souza and Souza (2004). It involves 10 items assessed on a Likert scale ranging from 1 (not a bit true) to 4 (exactly true). The score ranges from 10 points (low self-efficacy) to 40 (high self-efficacy). The results were categorised into low (11-22 points), medium (23-33 points), and high selfefficacy (34-40 points).

\section{Data analysis}

The Friedman and Kruskal-Wallis tests were used for intragroup (pretest, acquisition sessions, and retention test) and intergroup (retention test) comparisons related to the score of the front crawl. Significant effects were followed up using Wilcoxon and Mann-Whitney U tests.

Comparisons regarding the scale of self-efficacy beliefs involved the pretest and retention test. Intragroup analyses were run using the Wilcoxon test. Intergroup comparisons were made using the Kruskal-Wallis test followed by the Mann-Whitney U test. 
Analyses were conducted in two phases. First, general analysis comprised the three groups described previously: choice, yoked, and control. It was impossible to form separate groups of observation of the best and overall performances because 8 out of the 15 learners in the choice group opted to see video footages of their overall performances throughout the eight practice sessions. Of the remaining seven learners, one chose to watch his/her best performance in the first session, but from the second session switched to the overall performance. Three learners watched five times the overall performance then switched to the observation of their best performance during the $6^{\text {th }}$ session and then watched again their overall performance during the two remaining sessions. Two learners watched their best performance in the last practice session and one learner chose to watch his/her best performance in the $7^{\text {th }}$ session, but switched to the overall performance video again in the last session.

So, the second phase, or specific analysis, involved comparisons between the learners who changed their choices and those who did not (randomly selected) and their yoked counterparts. This procedure resulted in four groups: choice with change (CC); yoked to the choice with change (YCC); choice without change (CWC); and yoked to the choice without change (YCWC). For all analyses, the level of significance was set at $p<.05$, using SPSS 17 for Windows software. It is important to clarify that decision making on the statistical tests were preceded by the use of the Shapiro-Wilk's W and Bartlett's tests of normality and homogenity of variance. The interval nature of the data was also considered.

\section{Results \\ Intragroup comparisons in the front crawl swim measures}

Performances of all groups in the front crawl swim are illustrated in Figure 1. Considering the intragroup comparisons, the Friedman test revealed differences for the choice group $\left[\chi^{2}(\mathrm{n}=15\right.$, $\mathrm{df}=9)=122.908, \mathrm{p}<.01]$. The Wilcoxon test pointed out differences between the pretest, all acquisition sessions and retention test $(\mathrm{p}<.01)$. The acquisition blocks differed from each other and all of them were different from the retention test $(\mathrm{p}<.01)$.

For the yoked group, the Friedman test also revealed significant differences $\left[\chi^{2}(n=15\right.$, $\mathrm{df}=9)=81.469, \mathrm{p}<.01]$. Similar to the previous group, the Wilcoxon test pointed out differences between the pretest, all acquisition sessions and retention test $(p<.01)$. Differences were also observed between the first to the second and third acquisition blocks $(\mathrm{p}<.03)$; even the acquisition blocks differed from each other, all of them were different from the retention test $(\mathrm{p}<.01)$.

Finally, for the control group, the Friedman test also revealed significant differences $\left[\chi^{2}(n=10\right.$, $\mathrm{df}=9)=18.291, \mathrm{p}<.05]$, and the Wilcoxon test pointed out the following differences: between the pretest and eighth session $(\mathrm{p}<.05)$; the first and fifth session $(\mathrm{p}<.05)$; the third and fifth session $(\mathrm{p}<.03)$; and the fifth and sixth session $(\mathrm{p}<.05)$.

\section{Intergroup comparisons in the front crawl swim measures}

In the intergroup comparisons, the KruskalWallis test revealed significant differences on

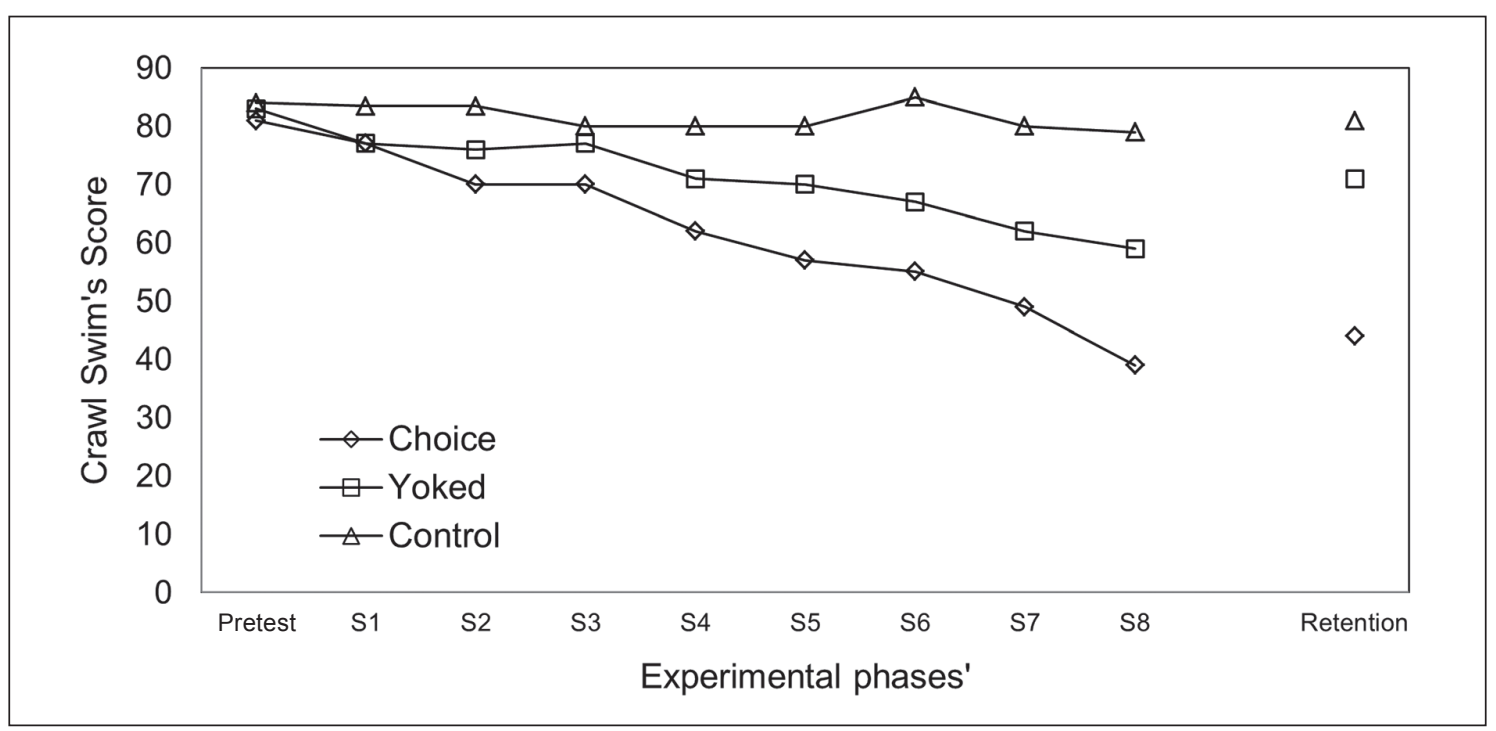

Figure 1. Performance of the choice, yoked and control groups in the front crawl swim in the pretest, acquisition and retention phases. 
the retention test $\left[\chi^{2}(\mathrm{n}=40, \mathrm{df}=2)=32.175, \mathrm{p}<.01\right]$. The Mann-Whitney U test showed that the choice group was different from both the yoked and control groups $(\mathrm{p}<.01)$ and that the yoked group was different from the control group $(\mathrm{p}<.01)$.

In sum, these results showed that motor learning occurred only for the choice and yoked groups. Furthermore, it was observed that motor learning for the choice group was superior to that of the yoked and control groups.

\section{Self-efficacy beliefs evaluation}

With regard to the intragroup comparisons, the Wilcoxon test revealed differences for the choice $(Z=-2,937, \mathrm{p}<.01)$ and yoked $(Z=-2,530, \mathrm{p}<.05)$ groups, which showed an increase in self-efficacy beliefs, but not for the control group $(Z=-1,826$, $\mathrm{p}>$.05). Concerning the intergroup comparisons, the Kruskal-Wallis test revealed differences after the acquisition phase $\left[\chi^{2}(n=40, d f=2)=13.152, p<.01\right]$. The Mann-Whitney U test pointed out differences between the choice and control group for the postacquisition phase $(\mathrm{p}<.01)$ and between the yoked and control group also in the post-acquisition phase $(\mathrm{p}<.02)$.

\section{Specific analysis from the choices in the front crawl swim measures}

Performances of the four groups in the front crawl swim are illustrated in Figure 2. and all sessions and the retention test $(\mathrm{p}<.02)$. The acquisition blocks differed from each other, and all of them were different from the retention test $(p<.05)$. The Friedman ANOVA also revealed significant differences for the YCC group $\left[\chi^{2}(\mathrm{n}=7\right.$, $\mathrm{df}=9)=31,244, \mathrm{p}<.01]$. Similar to the previous group, the Wilcoxon test pointed out differences between the pretest and other experimental phases $(p<.03)$. Differences were also observed between the first and second, third, fourth, and fifth acquisition blocks, and between the seventh and eighth blocks ( $\mathrm{p}<.05)$, but no differences occurred during the retention test ( $\mathrm{p}>.05)$. For the CWC group, the Friedman ANOVA revealed significant differences $\left[\chi^{2}(\mathrm{n}=8, \mathrm{df}=9)=66,850, \mathrm{p}<.01\right]$, and the Wilcoxon test pointed out differences between the pretest and all sessions and the retention test $(\mathrm{p}<.02)$. The acquisition blocks differed from each other, and all of them were different from the retention test $(p<.03)$. Finally, for the YCWC group, the Friedman ANOVA also revealed significant differences $\left[\chi^{2}(\mathrm{n}=8, \mathrm{df}=9)=52,914, \mathrm{p}<.01\right]$, and the Wilcoxon test pointed out differences between the second block and the rest of sessions and the retention test $(\mathrm{p}<.04)$.

Considering the intergroup comparisons on the retention test, the Kruskal-Wallis test revealed significant differences $\left[\chi^{2}(\mathrm{n}=30, \mathrm{df}=3)=21.819\right.$, $\mathrm{p}<.01]$. The Mann-Whitney U test showed differences between the $\mathrm{CC}$ and $\mathrm{YCC}$ groups $(\mathrm{p}<.01)$, and

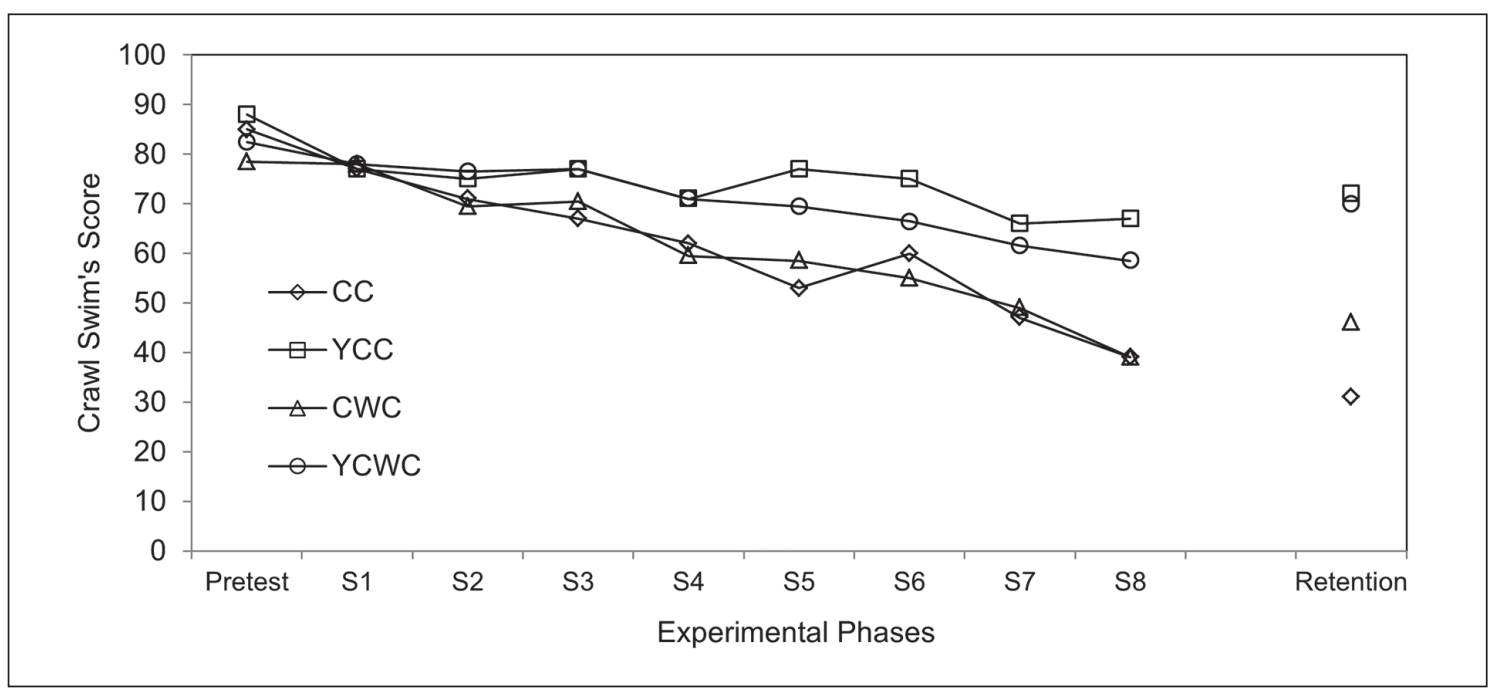

Figure 2. Performance of the choice with change (CC), yoked choice with change (YCC), choice without change (CWC), and yoked without change $(Y C W C)$ groups in the front crawl swim in the pretest, acquisition, and retention phases.

Concerning the intragroup comparisons, involving the pretest, acquisition, and retention test, the Friedman test revealed differences for the CC group $\left[\chi^{2}(n=7, d f=9)=56,875, p<.01\right]$. The Wilcoxon test pointed out differences between the pretest the CWC and YCWC groups ( $\mathrm{p}<.01$ ), but no differences were revealed for the $\mathrm{CC}, \mathrm{CWC}$ and yoked groups. In sum, these results showed that the choice opportunity was beneficial to the learning, whether or not there were changes. 


\section{Discussion and conclusions}

The aim of this study was to investigate the learners' choice in relation to self-as-a-model strategies in learning the front crawl swim during an eight-session practice. We decided to double the number of practice sessions with respect to previous studies (e.g. Marques \& Corrêa, 2016; Starek \& McCullagh, 1999) because we expected that by improving the learners' level of performance, we would enhance their need to watch their best performance.

Our expectancy was only partially confirmed because some learners altered their choices (e.g. switched from the overall to the best performance in the sixth practice session). Specifically, seven learners requested the at some stage in an effort to contrast what they received for feedback on their overall performance with what they did best. One learner chose to start the acquisition phase with the video of his/her best performance, but from the second session migrated to the video of overall performance. Three learners asked to change from overall performance to the best performance in the sixth session, and returned to overall performance video in the seventh session. Two other learners chose to watch the video of their best performance in the last practice session. One asked to watch his best performance in the seventh session, but returned to the overall performance in the eighth session. So, with the exception of one participant, all those who changed their choices did so from the sixth practice session onwards.

It appears that more practice results in a better mastery of the task's components and dimensions. In other words, the learner refines his/her needs on what to choose as the practice goes along and therefore some learners varied their choices only in the final part of the practice. In fact, the use of long periods of practice has been pointed out recently as an essential aspect in the studies about the factors affecting motor learning, including self-controlled learning (Gane \& Catrambone, 2011). Moreover, it is important to highlight that changes in the selfcontrolled learning occurred mainly towards the observation of the best performance.

Although there is guite a number of studies showing the benefits of the self-observing of one's own best performance (e.g. Clark, et al., 2006; Dowrick \& Raeburn, 1995; Hars \& Calmels, 2007; Starek \& McCullagh, 1999; Winfrey \& Weeks, 1993), it is hyphotesized that freedom of choice brings benefits from individual learning needs. Thus, in the final practice session several learners could have reached a performance level at which the greatest need was the one of parameterization, that is, adjustments of the details of the movement pattern, like the advanced learners do, as shown by the studies on self-observation of the best performance (e.g. Hars \& Calmels, 2007; Ste-
Marie, Rymal, Vertes, \& Martini, 2011a; Winfrey $\&$ Weeks, 1993). For instance, Ste-Marie, Vertes, Rymal, and Martini (2011b) used the self-observation of the best performance in gymnasts at a competitive level. The design consisted of either watching or not watching self-observation during the days of competition. The results showed that gymnasts had better scores on days when they watched videos containing their best performance. In the study, the authors employed a semi-structured interview based on the model of Zimmermann (2000) for self-regulation and found that gymnasts qualitatively employed self-regulatory processes when they had the opportunity to watch videos with their best performance. That is, they made use of self-assessment to develop strategies to achieve their goal that day.

According to Zimmerman (2013), understanding how to take advantage of freedom of choice takes some time and experience, but it can be very positive for learning. However, as mentioned before, many studies on self-controlled motor learning have used only a small number of sessions/blocks of practice trials, for example, the acquisition phase was performed during a single day (e.g. Andrieux, Danna, \& Thon, 2012; Patterson \& Carter, 2010) or a week (e.g. Clark \& Ste-Marie, 2007; Starek $\&$ McCullagh, 1999). Furthermore, these studies did not give the learners an opportunity to change their choice along practice so that these effects were unknown.

In this regard, in our study interestingly, all the learners except one chose to see their overall performance from the beginning to the final practice, even within the extended practice. Thus, self-observation of overall performance seems to be a suitable strategy for the needs of most learners (Marques \& Corrêa, 2016). Information related to the overall performance could be enough to fulfil the needs of most beginning and intermediate swimmers during their practice.

Regarding the self-efficacy belief results, the improvements noticed for the choice and yoked groups are in the line with results from Law and SteMarie (2005). They showed that by watching their own performance, skaters became more motivated with their self-efficacy beliefs higher and levels of anxiety lower. It is possible that throughout the practice sessions, swimming goals and individual strategies to reach them had become more specific to each learner (Cleary \& Zimmerman, 2001).

In conclusion, results showed better learning of the front crawl swim for the choice group as compared to the yoked and control groups. Results also showed that the belief of self-efficacy also improved for the choice and yoked groups. While most learners chose self-observation of their overall performance during all practice sessions, some others decided to switch their observations along 
practice. Both the best and overall perfomance observations had similar effects on learning the front crawl swim. It was concluded that providing learners with freedom of choice during the extended acquisition phase was beneficial to motor learning, regardless of whether or not there were changes in choices of videos. Further studies should investigate the effects of freedom of choice on learning the front crawl swim with advanced learners.

\section{References}

Andrieux, M., Danna, J., \& Thon, B. (2012). Self-control of task difficulty during training enhances motor learning of a complex coincidence-anticipation task. Research Quarterly for Exercise and Sport, 83, 27-35.

Bandura, A. (2006). Guide for constructing self-efficacy scales. In F. Pajares \& T. Urdan (Eds.), Self-efficacy beliefs of adolescents (pp. 307-337). Greenwich: Information Age Publishing.

Chiviacowsky, S., \& Wulf, G. (2005). Self-controlled feedback is effective if it is based on the learner's performance. Research Quarterly for Exercise and Sport, 76(1), 42-48.

Clark, S.E., \& Ste-Marie, D.M. (2007). The impact of self-as-a-model interventions on children's self-regulation of learning and swimming performance. Journal of Sports Science, 25(5), 577-586.

Clark, S.E., Ste-Marie, D.M., \& Martini, R. (2006). The thought process underlying self-as-a-model interventions: An exploratory study. Psychology of Sport and Exercise, 7(4), 381-386.

Cleary, T.J., \& Zimmerman, B.J. (2001). Self-regulation differences during athletic practice by experts, non-experts, and novices. Journal of Applied Sport Psychology, 13(2), 185-206.

Dowrick, P.W. (1999). A review of self-modeling and related interventions. Applied and Preventive Psychology, 8(1), 23-39.

Dowrick, P.W. (2012). Self-modeling: Expanding the theories of learning. Psychology Schools, 49(1), 30-41.

Dowrick, P.W., \& Raeburn, J.M. (1995). Self-modeling: Rapid skill training for children with physical disabilities. Journal of Developmental and Physical Disabilities, 7(1), 25-37.

Gane, B.D., \& Catrambone, R. (2011). Extended practice in motor learning under varied practice schedules: Effects of blocked, blocked-repeated, and random schedules. Proceedings of the Human Factors and Ergonomics Society, Annual Meeting, 55(1), 2143-2147.

Hars, M., \& Calmels, C. (2007). Observation of elite gymnastic performance: Processes and perceived functions of observation. Psychology of Sport and Exercise, 8(3), 337-354.

Law, B., \& Ste-Marie, D.M. (2005). Effects of self-modeling on figure skating jump performance and psychological variables. European Journal of Sport Science, 5(3), 143-152.

Madureira, F., Bastos, F.H., Corrêa, U.C., Rogel, T., \& Freudenheim, A.M. (2012). Assessment of beginner's frontcrawl stroke efficiency. Perceptual and Motor Skill, 115(1), 300-308.

Marques, P.G., \& Corrêa U.C. (2016). The effect of learner's control of self-observation strategies on learning of front crawl swim. Acta Psychologica, 164, 151-156.

Martini, R., Rymal, A.M., \& Ste-Marie, D.M. (2011). Investigating self-as-a-model techniques and underlying cognitive processes in adults learning the butterfly swim stroke. International Journal of Sports Science Engineering, $5(4), 242-256$.

McCullagh, P., \& Meyer, K.N. (1997). Learning versus correct models: Influence of model type on the learning of a free-weight lift. Research Quarterly for Exercise and Sport; 68(1), 56-61.

Newell, K.M. (1985). Coordination, control, and skill. In D. Goodman, R.B. Wilberg \& I.M. Franks (Eds.), Differing perspectives in motor learning, memory, and control (pp. 299-317). Amsterdam: North-Holland.

Patterson, J.T., \& Carter, M. (2010). Learner regulated knowledge of results during the acquisition of multiple timing goals. Human Movement Science, 29(2), 214-227.

Patterson, J.T., Carter, M., \& Sanli, E. (2011). Decreasing the proportion of self-control trials does not compromise the learning advantages in a self-control context. Research Quarterly for Exercise and Sport, 82(4), 624-633.

Ram, N., \& McCullagh, P. (2003). Self-modeling: Influence on psychological responses and physical performance. Sport Psychology, 17(2), 220-241.

Rymal, A.M., Martini, R., \& Ste-Marie, D.M. (2010). Self-regulatory processes employed during self-modeling: A qualitative analysis. Sport Psychology, 24(1), 1-15.

Souza, I., \& Souza, M.A. (2004). Validation of the General Self-Efficacy Scale. Revista Universidade Rural: Série Ciências Humanas, 26(1-2), 12-17.

Starek, J., \& McCullagh, P. (1999). The effect of self-modeling on the performance of beginning swimmers. Sport Psychology, 13, 269-287.

Ste-Marie, D.M., Rymal, A., Vertes, K., \& Martini, R. (2011a). Self-modeling and competitive beam performance enhancement examined within a self-regulation perspective. Journal of Applied Sport Psychology, 23(3), 292-307. 
Ste-Marie, D.M., Vertes, K.A., Law, B., \& Rymal, A.M. (2012). Learner-controlled self-observation is advantageous for motor skill acquisition. Frontiers in Psychology, 3, 556.

Ste-Marie, D.M., Vertes, K., Rymal, A.M., \& Martini, R. (2011b).Feedforward self-modeling enhances skill acquisition in children learning trampoline skills. Frontiers in Psychology, 2, 1-7.

Winfrey, M.L., \& Weeks, D.L. (1993). Effects of self-modeling on self-efficacy and balance beam performance. Perceptual and Motor Skills, 77(3pt1), 907-913.

Zimmerman, B.J. (2000). Attaining self-regulation: A social cognitive perspective. In M. Boekaerts, P.R. Pintrich \& M. Zeidner (Eds.), Handbook of self-regulation (pp.13-35). Burlington: Elsevier.

Zimmerman, B.J. (2013). From cognitive modeling of self-regulation: A social cognitive career path. Educational Psychology, 48(3), 135-147.

Submitted: May 6, 2016

Accepted: January 26, 2017

Correspondence to:

Priscila Garcia Marques

Maringa State University - UEM - Maringá,

Paraná, Brazil

5790 Colombo Avenue, Jardim Universitário,

Zip Code 87020-900

Maringá - PR, Brazil.

Phone: (+55) 4430111346

E-mail: priscila.garcia.marques@gmail.com 